\title{
Goiânia, a cidade genérica: estudo dos shopping centers
}

\author{
Elane Ribeiro Peixoto ${ }^{1}$ e Isabela Paiva Gomes Ferrante ${ }^{2}$
}

\section{Histórico dos shopping centers}

Tome 50 hectares de terreno plano. Contorne-o com 500.000 consumidores que não tenham acesso a nenhum outro arranjo comercial. Prepare o terreno e cubra a parte central com um milhão de metros quadrados de edifícios. Preencha-o com os melhores especialistas de técnicas comerciais que venderão, a preço baixo, artigos de qualidade. Decore-o todo com 10.000 vagas para estacionamento e assegure que o terreno seja acessível por excelentes vias expressas subtilizadas. Termine a decoração com plantas, parterres de flores, uma pequena escultura e sirva quente ao consumidor. (GRUEN) ${ }^{3}$

Pesquisas realizadas na Universidade de Harvard, intituladas Project on the city 2 (KOOLHAAS et al., 2001), têm por objeto o comércio em grande escala, tratado de uma forma geral, com destaque para os shopping centers. Um histórico do comércio compreendido entre a Basílica Romana (110 a.C.) e o mais moderno shopping center (2004) é parte da referida obra.

Como ponto de partida para o estudo desses objetos arquitetônicos tomaram-se as passagens parisienses, com a justificativa de que suas características arquitetônicas traziam os germens do que atualmente se conhece como shopping.

Antes de deter-se na análise propriamente dita das passagens, observa-se que a sensibilidade crítica de Benjamin (2000) identificou os elementos que propiciaram à receita citada na epígrafe deste texto as proporções e os temperos corretos para o objeto em questão se tornar uma das mais populares invenções do século XX. No texto Paris: capitale du XIXe siècle, o autor reconheceu os antecedentes das passagens em acontecimentos precisos. Embora a primeira passagem parisiense surgisse em 1786, o Palácio de Cristal (1851) e sua exposição evidenciaram o deslumbramento do homem comum diante do fetiche de máquinas, mercadorias, objetos brilhantes dotados de movimento e da recriação de uma natureza exótica trazida de terras distantes e tropicais para a chuvosa Londres. Esse personagem, o flanêur, em sua atitude blasé, dissolvia-se no espetáculo des-

\footnotetext{
${ }_{1}^{1}$ Mestre e doutora em Arquitetura e Urbanismo pela USP, com estágio na Maison des Sciences de L'homme (MSH), Paris. ${ }^{2}$ Aluna de Arquitetura e Urbanismo da Universidade Católica de Goiás, bolsista de Iniciação científica do CNPQ participante da pesquisa coordenada pela Prof. - Dra Elane Ribeiro Peixoto, Goiânia, cidade genérica.

${ }^{3}$ Prenez 50 hectares de terrain plat idéal. Entourez-les par 500000 consommateurs qui n'ont aucun autre accès à des aménagements commerciaux. Préparez le terrain et couvrez la partie centrale avec un million de mètres carrés de bâtiments. Remplissez avec les meilleurs spécialistes des techniques commerciales qui vendront à bas prix des articles de qualité. Décorez le tout avec 10000 parkings et assurez-vous de rendre le terrain accessible par d'excellentes voies express sous utilisées. Terminez en décorant avec des plantes, des parterres de fleurs variées, une petite sculpture et servez brûlant au consommateurs. (A tradução dos trechos citados é da primeira autora.)
} 
se mundo artificial, consumindo seu tempo livre em um estado de torpor e estupefação. Essa mesma atitude estava presente na deambulação realizada nas passagens com suas lojas e vitrines de luxo.

Enfim, como descrever as passagens parisienses? Para esse propósito, ninguém melhor para explicá-las do que o próprio Benjamin (2000, p. 48):

As passagens são nós para o comércio de artigos de luxo. Em seu arranjo, a arte serve ao comércio. Os contemporâneos não as deixam de admirar. Por muito tempo, permanecerão como atração para os turistas. Um guia ilustrado de Paris diz: "As passagens, recente invenção do luxo industrial, são corredores com tetos envidraçados e entablamentos de mármore que percorrem blocos inteiros de imóveis, cujos proprietários se socializavam com esse propósito de especulação. Nos dois lados da passagem, que recebe sua luz do alto, alinham-se lojas, as mais elegantes, de tal forma que se assemelha a uma cidade, um mundo em miniatura" ${ }^{4}$

As passagens datam do final do século XVIII e popularizam-se no século XIX, auxiliadas pelas transformações sofridas por Paris sob a batuta do Barão Haussmann. Pode-se inferir da descrição que esses edifícios pertenciam ao mundo do Ecletismo. A arquitetura do ferro, ainda insegura nas mãos dos arquitetos educados no sistema Beaux Arts, mimetizava materiais e formas, criava decorações e cenários para a exposição de objetos de luxo. Lá estavam presentes os processos de préfabricação que caracterizaram a arquitetura do ferro exportada para muitos lugares do mundo. No Brasil, em especial, destacavam-se nas cidades de São Paulo, Belém, Fortaleza, como bem o demonstram Geraldo Gomes (1987) e Beatriz Kühl (1998). A partir da França, essa tipologia arquitetônica e este hábito de comércio irradiaram-se pela Europa e atingiram os Estados Unidos da América. Londres, Milão, Bruxelas entre tantas outras cidades do planeta contaram com esses objetos arquitetônicos como parte de sua fisionomia, cujo exemplo relevante é a galeria Victorio Emanuell.

É importante observar na descrição feita a referência a um mundo miniaturalizado, que simula a cidade, mas lhe subtrai a rotineira balbúrdia. À artificialidade da rua corresponde a sublimação das tensões sociais. Outra interessante referência é a iluminação zenital, a qual foi possível por meio das coberturas de vidro, e capaz de oferecer proteção contra as variações climatológicas. O controle do ambiente, assim, estava programado.

O grande magasin, mais um elo na genealogia do shopping center, ganhou notoriedade em lojas como a galeria Lafayette (1893), Harrod's (1849), Samaritaine (1869). Esses magasins, reservados ao comércio de luxo, funcionavam com uma nova forma de tratamento dirigida ao consumidor

\footnotetext{
4 «Les passages sont des noyaux pour le commerce des marchandises de luxe. En vue de leur aménagement l'art entre au service du commerçant. Les contemporains ne se lassent pas de les admirer. Longtemps ils resteront une attraction pour les touristes. Um Guide illustré de Paris dit: "Ces passages, récente invention du luxe industriel, sont des couloirs au plafond vitré, aux entablements de marbre, qui courent à travers des blocs entiers d'immeubles dont les propriétaires se sont solidarisés pour ce genre de spéculation. Des deux côtés du passage, qui reçoit sa lumière d'en haut, s'alignent les magasins les plus élégants, de sorte qu'un tel passage est une ville, un monde en miniature".
} 
definida pela relação direta entre esse e o produto, em que se observa um primeiro distanciamento interpessoal com a dispensa do solícito vendedor.

As lojas de departamento derivaram dos grandes magasins, sendo a pioneira entre essas o Au Bon Marche, datada de 1852. Segundo Crawford (2004), Zola situou seu romance Au Bonheur des Dames nesse famoso magasin. Sua descrição confirma a astuta atitude do comércio em transformar $\mathrm{o}$ ato de consumir em fonte de espetáculo, fascinação e fantasia. Os ambientes interiores dessas lojas magnificaram-se com decorações do universo maravilhoso, como a recriação de ambientes egípcios da atual Harrod's, aproximando esses empreendimentos aos parques de diversão, às exposições mundiais e, num salto no tempo, ao mundo da cultura de massa, identificado com Las Vegas. Após a década de 1930, as lojas de departamento espalharam-se para as periferias das grandes cidades americanas, prenunciando o aparecimento dos shoppings. Ressalta-se que, inseridas na sociedade de massa do século $\mathrm{XX}$, essas lojas adquiriram, muitas vezes, um caráter mais popular. Posteriormente transferiram-se, em sua grande maioria, para o interior dos shoppings, onde assumiram a função de lojas-âncoras.

O primeiro shopping, segundo a tipologia conhecida, data de 1956 e foi construído em Minneapolis, nos Estados Unidos, pelo arquiteto Victor Gruen. Algumas outras experiências com características peculiares o precederam, como, por exemplo, o fato de serem abertos. A partir desse primeiro shopping, observa-se que sua estrutura espacial permaneceu quase inalterada, com licenças para uma ou outra variação. O sucesso e a hegemonia política dos Estados Unidos pós-Segunda Guerra Mundial transformaram essa forma de comércio numa espécie de epidemia que se alastrou na mesma velocidade do capital internacional e corporativo.

Duas inovações tecnológicas utilizadas nas lojas de departamento e nos magasins foram essenciais para o desenvolvimento e o sucesso dos shoppings centers: a escada rolante e o arcondicionado (KOOLHAAS et al., 2001). A refrigeração mecânica permitiu o desenvolvimento de um ambiente confortável para o consumidor, livrando-o das variações climáticas. Porém, o avanço permitido por essa tecnologia foi a extensão ilimitada desses edifícios, englobando uma enorme variedade de comércio atacadista. Para Weiss e Leong (2001), assim como o ar- condicionado, a escada rolante foi central no desenvolvimento do tipo arquitetônico do shopping, pois permitiu o deslocamento de grande contingente humano por largas extensões, abolindo a fadiga que tal empreendimento provocaria. Não surpreende, portanto, a extensão do shopping de West Edmonton (Alberta, Canadá), cuja área é de $483.000 \mathrm{~m} 2$, sendo sua superfície maior do que a de cem campos de futebol (Crawford, 2004). Esse mastodonte do consumo merece uma digressão. O ensaio "El mundo en um centro comercial" (CRAWFORD, 2004, p.15) contém descrições que auxiliam na definição da tipologia arquitetônica do shopping. Como volume, esse objeto arquitetônico é descrito como "um amontoado 
descuidado de caixas em meio a um enorme mar de asfalto, rodeadas por paisagem interminável de casas unifamiliares". Trata-se de descrição que corresponde exatamente à receita formulada por Gruen. Esse arranjo espacial corresponde também à arquitetura descrita por Venturi em Aprendendo com Las Vegas (VENTURI et al., 2003) e diz respeito à tipologia do galpão decorado. Nesse, os sistemas espacial e estrutural estão submetidos ao programa, e a ornamentação limita-se a uma aplicação sobre a caixa arquitetônica. Se Venturi reportava-se, sobretudo, aos cassinos, cujas fachadas estavam cobertas por formas e motivos desenhados por uma iluminação feérica, no caso dos shoppings a decoração vincula-se aos logotipos não menos brilhantes.

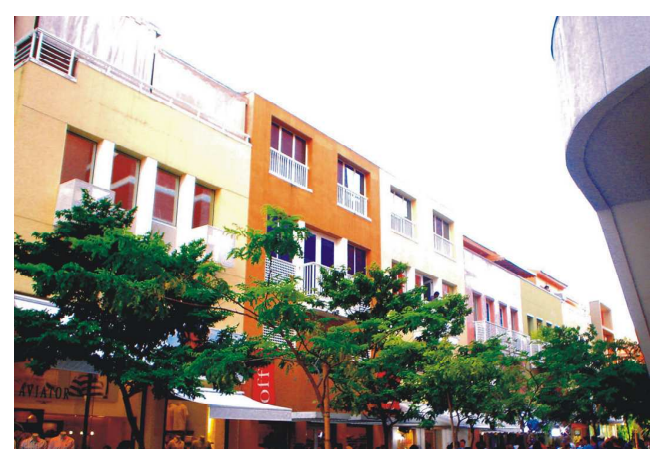

Retomando a descrição de West Edmonton, seu espaço interior sugere um delírio. Nele convivem caravelas (Santa Maria), pontes vitorianas, submarinos autênticos, algas de plástico, pingüins vivos e tubarões de borracha, controlados automaticamente, todos dispostos em infinitos pátios sucessivos iluminados zenitalmente. Natureza e artifício postos lado a lado significam a abolição do tempo e da história no eterno presente do consumo. Embora delírio e

confusão possam parecer inéditos, eles já estavam contidos em potência nas grandes exposições universais, nas passagens descritas por Benjamin, na indústria do entretenimento, exemplificada nos parques americanos de Coney Island. ${ }^{5}$

Nas mesas dos incorporadores, nas pranchetas ou computadores de desenhistas, os shoppings ganharam as mais diversificadas variações estilísticas: das caixas suportes para as logomarcas trilharam os "alegres" caminhos do pós-

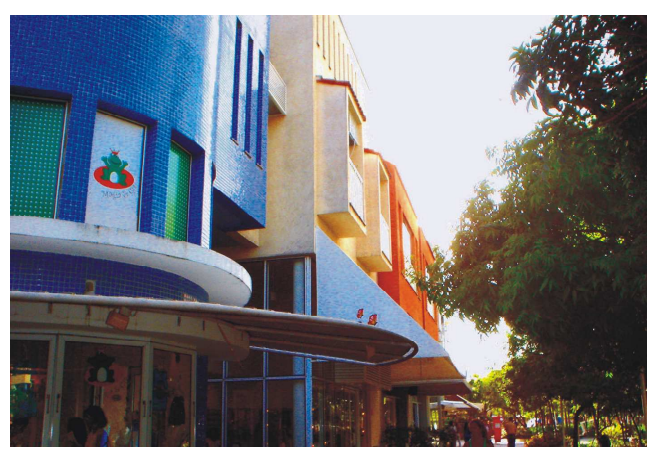

Shopping Down Town - Rio de Janeiro À maneira de um parque temático, este shopping simula um centro tradicional de cidade.

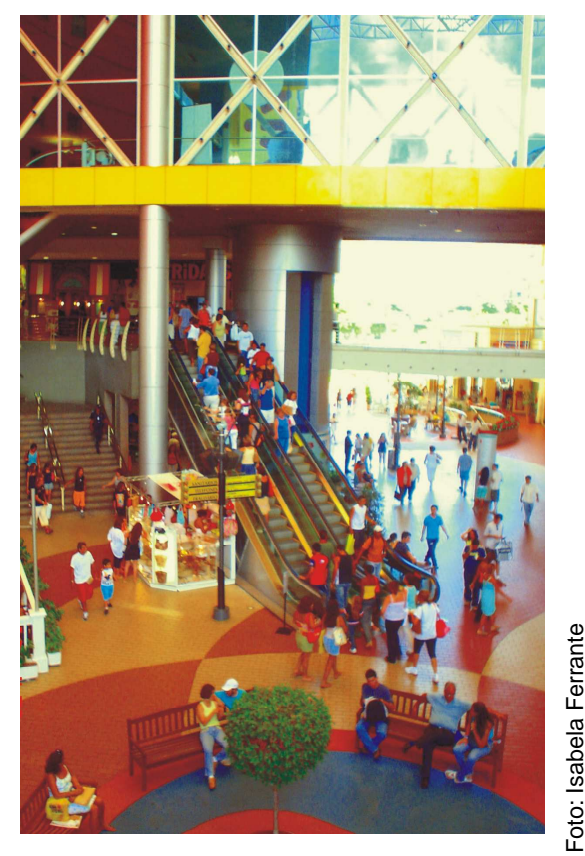

New York - Shopping no Rio de Janeiro modernismo, com a presença de torres, frontões, criados à

\footnotetext{
${ }^{5}$ Dois parques construídos em Coney Island são referências obrigatórias: O Luna Park (1893) e o Dreamland (1904). Ambos destinavam-se à diversão das massas e incorporavam as novidades movidas à eletricidade. Eram lugares cercados por muros e suas entradas estavam marcadas por pórticos monumentais. No interior desses parques havia atrações tais como cavalos mecânicos, montados sobre trilhos em plano descendente e que se moviam por força da gravidade, simulando corridas e competições. Em Dreamland, espetáculos organizados sob a ação de bombeiros em luta contra o fogo eram oferecidos e atraíam grande quantidade de público. O mesmo interesse era voltado para simulação de uma cidade liliputiana, habitada por anões. O urbanismo Disney encontrava-se aí esboçado.
} 
semelhança das estórias infantis. Não pararam por aí. Como objetos submetidos à dinâmica da moda, tiveram versões estilísticas em alta tecnologia, mediocremente associadas aos muitos metros quadrados de Alucobond. Não faltaram as cúpulas que rememoram as estufas vitorianas do século XIX ou os centros urbanos fictícios compostos pela modalidade dos shoppings abertos, tais como Downtown ou New York, ambos no Rio de Janeiro.

A necessidade de ser atual implica a constante renovação desses edifícios, o que os obriga a sobreviver por meio da sobreposição de revestimentos e fachadas. Essa demanda pressupõe construções facilmente renováveis que substituem os materiais perenes pelos descartáveis e os aproxima da idéia de junkspace formulada por Koolhass (2000, p. 744-745):

Junkspace é aquilo que resta quando a modernização está em curso, ou melhor, é aquilo que se coagula na medida em que essa modernização se realiza [...].

Junkspace é o fruto do encontro da escada rolante e do ar-condicionado, concebido em uma incubadora em gesso acartonado (três ausências nos livros de histórias). Junkspace é um corpo duplo do espaço, o território de uma ambição revista de forma rebaixada, de desesperança e de importância reduzida. Junkspace é o triângulo das Bermudas do conceito, é um prato frio e abandonado, abaixa a barreira imunológica, anula as distinções, abala a solidez, confunde a intenção com a realização. [...]

A continuidade é a essência do Junkspace. Ele explora não importa qual seja a descoberta que facilite sua expansão, envolve todos os dispositivos que servem a desorientar (espelhos, superfícies polidas, ecos), desdobra toda uma infra-estrutrura do contínuo: escadas rolantes, sprinkers, portas corta-fogo, redes de aquecimento e ar-condicionado [... ]. Junkspace é hermeticamente fechado, não é a estrutura que o sustenta, mas a tensão de sua superfície, ele é como uma bolha ${ }^{6}$

As imagens suscitadas pelo autor são metáforas que auxiliam a compreender a artificialidade do shopping center. Enquanto coágulo dos processos de modernização, justifica-se nos seus restos e múltiplos acréscimos, certamente tornando-se um objeto valioso para um arqueólogo do futuro. A referência à bolha e a tensão de sua superfície remetem ao mundo artificial das estufas e à recriação de naturezas insólitas.

\footnotetext{
${ }^{6}$ Junkspace, c'est ce qui reste quand la modernisation est à bout de course, ou, plutôt, c'est ce qui se coagule au fur et à mesure qu'elle se fait [...]

Junkspace est le fruit de la rencontre de l'escalator et de l'air conditionné, conçue dans un incubateur en placoplâtre (trois choses qui sont absentes des livres d'histoire). Junkspace est le doublé corps de l'espace, le territoire d'une ambition revue à la baisse, d'espérance limitée et d' importance réduite. Junkspace est le triangle des Bermudes du concept, un plat refroidi et délaissé; il abaisse la barrière immunitaire, anulle les distinctions, sape la fermeté, confond l' intention avec la réalisation. [...]

La continuité est l'essence de Junkspace. II exploite n' importe quelle trouvaille qui facilitera l'expansion, enrôle tous les dispositifs qui servent à désorienter (miroirs, surfaces polies, échos), dêploie toute une infrastructure du continu: escalators, sprinkler, coupe-feu, rideaux d'air chaud, air conditionné... Junkspace est hermétiquement clos, ce n' est pas la structure qui le fait tenir mais sa tension superficielle, comme une bulle.
} 
Enquanto triângulo das Bermudas do conceito, os shoppings não se caracterizam por uma ausência, mas sim pela instabilidade que Ihe ordena e configura. Deriva daí sua constante submissão a um eterno fazer, desfazer, refazer, a opção pelos materiais e mecanismos que lhe permitem um estado latente de transformação.

O hermeticamente fechado induziu uma recriação da natureza, ensejando técnicas que a possibilitem. A descrição de uma palmeira replascape corrobora para compreender essa simulação:

As palmeiras do "replascape" são, em geral, verdadeiras árvores cultivadas sobre controle das estufas e que foram cortadas depois de haverem atingido um tamanho e circunferência desejados; são, então, cuidadosamente dissecadas em um laboratório que lembra as salas posteriores de um necrotério. Cada seguimento do invólucro exterior de seus caules e suas folhas é retirado, secado e imerso em um líquido de embalsamento, posteriormente autorizado à secagem. É, então, que intervêm os experts e artesãos que reconstituem as árvores, tecendo seus seguimentos de tronco, unindo-os com um tubo de PVC. "Cabeças em aço receptíveis", contendo até quarenta pontos de ligação são, então, inseridas no topo desses tubos, com o propósito de receber as folhas preservadas. Amputadas de suas raízes, "as palmeiras preservadas não mais necessitam de jardineiras especiais", a tal ponto que, segundo um fabricante de replascape, "coloca-se simplesmente o tronco no solo". (CHA et al., 2001, p.144)

A simulação não se restringe à natureza, mas desenvolve-se no falseamento do espaço urbano, expresso em denominações tais como praça, alamedas, e, muitas vezes, no uso de mobiliário próprio ao espaço citadino.

\section{O segredo da caixa}

O segredo do shopping center é não ter segredo algum. Sua tipologia sintetiza-se à primeira vista na receita de Gruen, porém, voltando a atenção para seu interior, observam-se duas variações no arranjo de fluxo e lojas, desenvolvidas após sua criação.

Essas variações foram denominadas, por Herman (2001), dumbbell e cluster. A primeira é definida pela separação das massas construídas por uma circulação linear seccionada por passagens, cujo exemplo mais puro encontra-se em Northgate Center (Seatle, 1950), projetado por John Graham. O cluster define-se pelo agrupamento de massas edificadas percorridas por um sistema de circulação em seus interstícios, como uma rede de interseções. Seu primeiro exemplo é o Northland Shoppig Center (Detroit, 1954), de Victor Gruen.

Herman demonstra, com uma série de exemplos, que os tipos identificados muitas vezes associam-se, gerando modelos híbridos. Se algum segredo pode ser vislumbrado nesses enormes centros de consumo, diz respeito à eficácia de venda do empreendimento. Em palavras claras, isso significa as pesquisas de marketing que lhes antecede, a locação de espaços privilegiados e estraté- 
gicos às lojas capazes de atrair um grande número de consumidores e, por fim, o bombardeamento publicitário que os torna atrativos.

As pesquisas de marketing implicam a análise de uma gama complexa de variáveis que terminam por gerar uma cartografia urbana do consumo, definindo $\mathrm{m}^{2} /$ por consumidor, dimensionando estacionamentos e número de lojas, entre tantas outras questões. Dessa forma, ao projetista cabe racionalmente propor circuitos e situar convenientemente as chamadas lojas-âncoras. O espaço restante é distribuído segundo uma modulação, em um conjunto menor de comércio formado por lojas chamadas satélites. Âncoras e satélites ensejam uma nova nomenclatura, mix, que se refere à variedade do comércio a varejo. Talvez, o segredo da caixa seja decifrar o significado de seu vocabulário, tais como âncora hard e soft, mall, ABL, life style - nada que um bom dicionário de língua inglesa, associado a um pouco de imaginação, não resolva.

A receita proposta por Victor Gruen no início dos anos de 1950 é em sua base ainda atual, embora os shoppings sempre respondessem à ordem do dia do discurso arquitetônico, em nível rebaixado - pós-modernismo, alta tecnologia e discursos ecológicos sustentaram inúmeras experiências disseminadas pelos quatro cantos do planeta $(N, S, L W)$, embora ele seja redondo.

Atualmente, assiste-se à fusão dos shoppings e dos parques temáticos, como foi bem exemplificado na referência feita ao West Edmonton. Enfim, o velho espírito das exposições universais ganha novo alento. O maravilhoso, agora, manifesta-se na estética kitsch de caravelas, mickeys, fontanas de trevi, entre outros. Um mundo autônomo afirma-se no interior desse amontoado de caixas gigantescas e mares de estacionamento.

A lógica do shopping expõe um outro papel atribuído aos seus projetistas, distanciados dos "puros" propósitos que durante um longo período do século XX alimentaram suas práticas profissionais. Sua importância é desviada para os projetos da racionalidade de movimentos, modulações, instalações extensíveis e criação de mundos artificiais, povoados por sereias, golfinhos e florestas tropicais. Paradoxos não tão facilmente perceptíveis para os que estão imersos neste mundo do fazde-conta. Atributos essenciais para esses projetistas parecem ser uma personalidade esquizofrênica e masoquista, a qual é capaz de lidar com a mais objetiva racionalidade técnica, com um fantástico mundo de alucinações e submeter-se às mais torturantes exigências de incorporadores. Do resto ocupa-se a publicidade.

Os shoppings sustentam a tese defendida por Kollhass em Delirious in New York (2004), sobretudo no que diz respeito à artificialidade do novo mundo e quiçá de sua congestão. Mesmo que isolados no meio de um nada e atravessados por autopistas, essa congestão é um fenômeno próprio ao seu interior: solicitações de todas as ordens impregnam os sentidos e impulsionam o consumo. A 
precedência de Coney Island e seus anômalos centros de diversão prefiguraram o casamento feliz do shopping e do parque temático - mais um exercício para os projetistas diligentes.

\section{Terra de Vera Cruz}

E assim seguimos o nosso caminho por este mar - de longo - até que na terça-feira das Oitavas de Páscoa - eram os vinte e um de abril - estando dita ilha distante de 600 a 670 léguas, conforme dados dos pilotos, topamos alguns sinais de terra: uma grande quantidade de ervas compridas, chamadas botelhos pelos mareantes, assim como outras a que dão o nome de rabo-de-asno. No dia seguinte - quarta-feira pela manhã - topamos aves a que os mesmos chamam de fura-buchos. Neste mesmo dia, à hora da véspera, avistamos terra! Primeiramente um grande monte, muito alto e redondo; depois, outras serras mais baixas, da parte sul em relação ao monte e, mais, terra chã. Ao monte alto o Capitão deu o nome de Monte Pascoal; e à terra, Terra de Vera Cruz. ${ }^{7}$

Latitude 1643'10,57"S e longitude 4915'36,96" W são coordenadas que marcam, desde 1937, um ponto sobre o mapa do Brasil, na região Centro-Oeste desse país, e localizam uma cidade chamada Goiânia.

Criada como estratégia de ocupação do interior brasileiro, a fundação dessa cidade prosseguiu o processo da colonização portuguesa que comprimiu os espanhóis entre a Cordilheiras dos Andes e o Oceano Pacífico. O arquiteto carioca Atílio Corrêa Lima, pós-graduado pelo Instituto de Urbanismo Francês, foi responsável por seu projeto urbanístico. Goiânia, pode-se dizer, foi no Brasil a experiência pioneira de se fazer cidades, segundo processos e métodos que caracterizaram a ciência nascente.

Seu desenho inicial conjugava duas visões distintas, porém contemporâneas: de um lado o urbanismo derivado das experiências haussmanianas e de outro a sedução das cidades-jardins inglesas e americanas. A estética monumental do urbanismo próprio à escola francesa inspirou Corrêa Lima no desenho da cidade à semelhança de Versalhes. Posteriormente, a intervenção de outro arquiteto, Armando Augusto de Godói, suavizou o plano original da cidade com a criação de um bairro-jardim com feições pitorescas. A cidade, batizada em homenagem à tribo indígena dos Goyazes, construiu-se em pleno cerrado, paisagem assemelhada à savana.

\footnotetext{
${ }^{7}$ Trecho da carta de Pedro Vaz de Caminha, escrita em 1500, endereçada a D. Manuel de Avis descrevendo o descobrimento do Brasil.
}

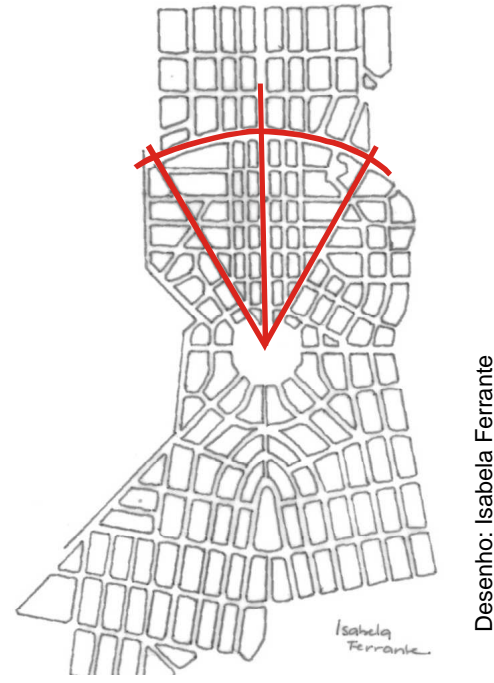

Projeto da Cidade de Goiânia - Atílio Corrêa Lima.

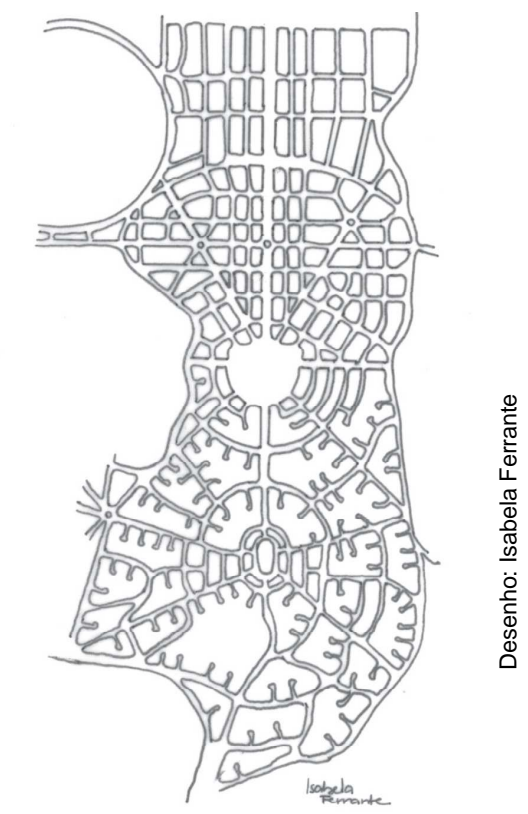

Projeto para o Setor Sul do arquiteto Armando Augusto de Godói. 
Mello (2004) em suas pesquisas constatou que a cidade, sede da nova capital política do estado de Goiás, teve o Palácio do Governo demarcado no solo de terra vermelha com

o fêmur de uma ema, ave semelhante à avestruz, porém menor,

e que é característica dessa região do Brasil. A pesquisadora defende a ema como o verdadeiro símbolo da cidade, baseada

na presença de inúmeras imagens em pinturas rupestres. Reivindicar essa ave como símbolo da cidade não é outra atitude, senão de sublinhar o isolamento do lugar em que foi construída.

Para Goiânia, concorreram muitos imigrantes, que, alojados em seus limites, foram os responsáveis por sua construção. O carro de boi, a bicicleta e a jardineira, uma espécie de ônibus com o motor na parte frontal, foram os meios comuns de transporte que transitaram pelas ruas poeirentas da novíssima capital de Goiás, cuja construção legitimou-se por meio de discursos e argumentos a favor da salubridade.

O crescimento da capital de Goiás acompanhou o ritmo de muitas cidades brasileiras, segundo a dinâmica da construção e destruição que Ihes foram próprias. De cidades horizontais, semelhantes às européias (não se deve olvidar que o ideal civilizatório para o Brasil do século XIX até o fim de Segunda Guerra Mundial foi a França), transformaram-se numa velocidade vertiginosa em cidades verticalizadas, aos moldes norte-americanos. Nos anos de 1960 o centro de Goiânia viveu uma mudança de escala e densidade, novos edifícios em altura foram, aos poucos, substituindo as casas ecléticas modestamente ornamentadas e obscurecendo seus não menos desimportantes edifícios públicos.

Com a construção de Brasília (1957), as redes de conexão da capital goiana solidificaram-se diante do avanço da estrada de ferro e de rodagem ligando-a à região Sudoeste do País. Vencer os novecentos quilômetros que a separavam de São Paulo tornou-se menos árduo, à medida que se avançou no século XX. Antes que essa rede se consolidasse e as trocas comerciais se tornassem mais dinâmicas, o sistema de abastecimento da cidade fazia-se segundo um circuito de produção e distribuição locais. As fazendas próximas produziam e beneficiavam os gêneros alimentícios, que, posteriormente, eram vendidos em armazéns e vendas.

Com Brasília, Goiânia rompeu seu isolamento e, definitivamente, americanizou-se, como exemplifica o aparecimento dos supermercados e das lojas de departamento. A transformação não se deu como em um passe de mágica. Ainda nos anos de 1970, as roupas finas eram trazidas de São Paulo e Rio de Janeiro para serem vendidas em boutiques, locais de atualização das elites. Costureiras, vindas dos subúrbios, trabalhavam nas casas de família da classe média, confeccionando numerosos vestidos por dia, para irmãs que dividiam o mesmo quarto e dormiam em camas dispos- 
tas segundo uma ordem de responsabilidade atribuída pela idade - a primeira filha ao lado da terceira e a segunda ao lado da caçula. As máquinas Singer só eram interrompidas ao meio-dia, hora do almoço, e às seis da tarde, quando pilhas de roupas estavam prontas, restando à dona da casa o trabalho dos arremates finais - uma bainha mais complicada, alinhavos a serem retirados, botões a pregar.

Os eletrodomésticos, bicicletas e panelas de todos os tipos estavam disponíveis em lojas de proprietários goianos, distantes da realidade das redes de hipermercados. O comércio estava nas ruas da cidade, ainda no seu centro tradicional. À medida que a população de maior poder aquisitivo deslocou-se para outros bairros e optou por viver em apartamentos, os pontos tradicionais de comércio sofreram alterações, sendo essas mais visíveis com o aparecimento do primeiro shopping center, precedido por galerias comerciais, como a sugestiva Galeria Vip, destinada ao comércio de vestuário. San Remo, A Pequetita, Jaqueline, San Ciro, Joãozinho e Maria, Lojas Garcia, A Evolução são nomes de lojas que já não existem mais nas fachadas modificadas por apliques de paraline no centro de Goiânia. Paulatinamente, as lojas tradicionais fecharam suas portas, desocupando velhos casarões normandos, logo transformados em imobiliárias, agências de viagem ou em comércio de artigos populares. O shopping center se fazia anunciar.

No Brasil o primeiro shopping, como não poderia deixar de ser, foi construído em São Paulo em 1966 e batizado Iguatemi o mesmo nome indígena da rua onde estava localizado - certamente como forma de aclimatar uma espécie estrangeira. Seria esse um velho e anacrônico jogo roubado ao Romantismo do Segundo Império ${ }^{8}$ Porém, foi na década de 1980 que a interiorização dos shoppings, quase repetindo a velha façanha de antigos bandeirantes, aconteceu. Nesse rumo da Marcha para o Oeste, encontrava-se Goiânia. Em outubro de 1981 o primeiro desses estabelecimentos foi inaugurado e batizado com o nome da árvore de Madagascar transplantada para a Terra Brasilis, o Flamboyant (Delonix regia). Explicam os empreendedores que o nome escolhido devia-se ao fato de ser essa árvore a pre-
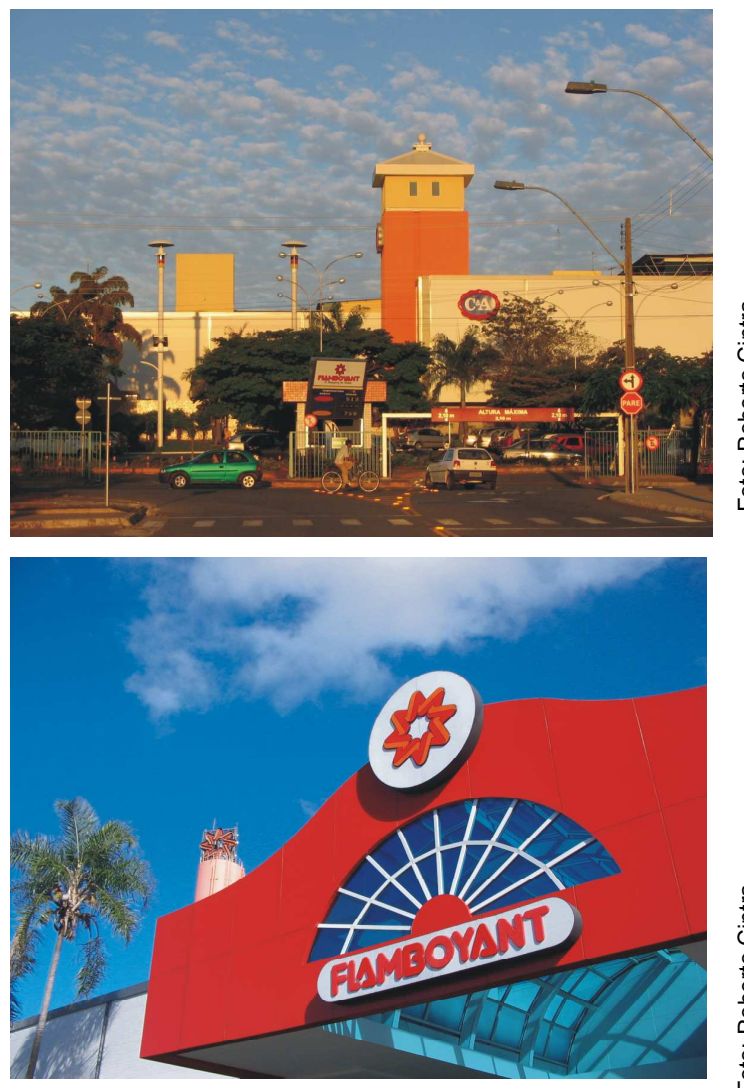

Shopping Flamboyant - Goiânia

\footnotetext{
${ }^{8}$ A rua em que foi construído o Iguatemi tinha esse mesmo nome. Essa opção parece conveniente e há de se lembrar que a prática do uso de nomes indígenas foi utilizada no Romantismo e por D. Pedro II, que se empenhou na participação de exposições universais, criando seus pavilhões, contribuindo para afirmar o exótico e único império americano.
} 
ferida dos goianos, principalmente na primavera. Por um raciocínio tortuoso concluíram que, por ser o "shopping totalmente fruto de Goiás", seu nome justificava ser o da árvore apreciada por seus habitantes. Nomear os shoppings com nomes de plantas tornou-se um consenso na cidade, quase transformada em um exótico jardim botânico. Ao Flamboyant sucederam o Shopping Bougainville (Bougainvillea spectablis), Buriti Shopping (Mauritia flexuosa $L$ ) e, entre os mais populares, o Banana Shopping (Musa $X$ paradisíaca $L$ ). Entre todos, para se fazer justiça, a única planta característica dessa região é o Buriti, uma espécie de palmeira que cresce em alagados.

$\mathrm{O}$ arquiteto idealizador do Flamboyant refere-se a sua concepção esclarecendo sobre a minuciosa pesquisa empreendida. Foram quatro anos de estudos e viagens aos Estados Unidos e Europa. O modelo americano tornou-se claro e seus mistérios desvendados. O shopping de Goiânia deveria ser construído na proximidade de eixos viários, prevendo seu alcance em escala regional - 0 mall americano cravava sua bandeirinha estrelada em terras que, há muito pouco tempo, eram pastos selvagens e abrigo de emas. A novidade do Flamboyant, comparado aos shoppings de São Paulo e Rio de Janeiro, residia na sua maior fidelidade à referência americana, tendo em vista que os construídos nas duas maiores cidades brasileiras eram indubitavelmente empreendimentos urbanos, distantes de rodovias e, portanto, limitados a cumprir a meta ambiciosa de se tornarem centros regionais de comércio e compras.

Situado em uma esquina rodoviária, O Flamboyant Shpopping Center causou furor e grande expectativa. Afinal, Goiânia entrava na "era do shopping", como anunciavam manchetes jornalísticas da época, que esclareciam sobre o esforço de longa data da capital de integrar-se ao cenário nacional. Encartes preciosos alardeavam o conforto de um centro de compras climatizado, em lugar onde a temperatura externa varia entre $25^{\circ}$ a $35^{\circ}$ centígrados, sob um sol inclemente. Corpos libertos dos suores provenientes de longas caminhadas pelas ruas da cidade estavam, assim, mais aptos para o consumo. Não faltaram aos anúncios, veiculados no mais importante jornal da cidade, menções à fabulosa escada rolante e ao espetacular elevador panorâmico, projetado especialmente para o Flamboyant Shopping Center e fabricado pela Otis, como esclarece seu projetista. Os novos aparatos tecnológicos eram saudados:

Elevador Panorâmico

Aquele que aparece nos filmes americanos, o Flamboyant tem. Ele leva você da praça do térreo I ao térreo II e depois ao terraço. Uma subida ou descida emocionante durante a qual você tem uma visão de toda a parte interna do Flamboyant com todas as vitrines explodindo em um mundo de cores. Uma viagem inesquecível. Um verdadeiro sonho realidade

\section{Ar condicionado}

Respire fundo. Você já está sentindo o arzinho gostoso climatizado e permanente, em qualquer época do ano. Faça sol de rachar ou faça chuva de alagar, no Flamboyant o clima é sempre este: gostoso para comprar, lanchar, divertir-se e passear. 


\section{Escada rolante}

No Flamboyant há oito para você subir ou descer. Descer ou subir. Subir ou descer. Bom, você é quem decide. A única certeza que temos é que você sempre vai encontrar uma loja cheinha de novidades pela frente ${ }^{9}$

Um evento inédito aconteceu no canteiro de obras para apresentar à elite local, não totalmente ignorante no assunto, o novo conceito de consumo. Um desfile de modas teve por cenário o edifício em construção, sendo os locais da obra que representavam riscos isolados. Mais uma vez, no meio de um outro deserto, um famoso estilista carioca apresentou suas criações à gente importante de Goiânia. Possivelmente mulheres arruinaram seus sapatos de salto alto equilibrando-se sobre as irregularidades do piso de um edifício em construção - mas o que significa um sapato diante de tão espetacular apresentação? Modelos trazidos do Rio de Janeiro desfilavam seus corpos magérrimos ao ritmo do Saturday night fever e apresentavam o dernier crit de Copacabana e Ipanema. Goiânia sincronizava-se com as mais importantes cidades do País.

A seqüência de anúncios em jornais da cidade acentua a importância atribuída ao seu novo centro de comércio:

\section{Nível Internacional}

Goiânia, como outras grandes cidades brasileiras, terá em breve seu shopping center de nível internacional. Conta a empresa publicitária da divulgação do Flamboyant que o considera um universo de compras e lazer criado especialmente para atender as exigências do consumidor goiano. Suas 130 lojas, racionalmente distribuídas e representando todos os ramos de varejo, serão atração permanente, constituindo-se em verdadeira passarela de quase um quilômetro de vitrines ininterruptas. Com estacionamento arborizado e dimensionado para abrigar dois mil automóveis de uma só vez, o Flamboyant poderá atender a uma população diária de 40.000 pessoas em suas avenidas internas, ao abrigo da chuva e do sol, em ambiente totalmente climatizado. Este é um dos mais modernos projetos em construção hoje no país. (O Popular, 10 maio 1980)

Flamboyant Shopping Center: empreendimento que representa maturidade técnica e econômica

[...] Capital moderna, pólo econômico e estratégico no processo do desenvolvimento do CentroOeste, Goiânia, apesar de todo seu potencial dispõe de poucas alternativas de facilidade de compras em sua estrutura atual de varejo. Ainda oferece a visão de uma geografia comercial concentrada no centro da cidade. E porque não possui opções, o goianiense, habitualmente, faz compras em outros centros, principalmente Brasília, São Paulo e Rio de Janeiro - dizem os diretores do Jardim Goiás Empreendimentos.

[...] A distribuição das lojas ao longo das alamedas internas (malls) foi feita segundo um plano orientado por uma empresa especializada em shopping center, a Nordal Associates Inc., com o intuito de provocar a circulação do público à frente de todas as lojas e entre os pavimentos.

( Folha de Goiáz, 8 maio 1980)

Goiânia, 48 anos, 800 mil habitantes, entra na era do "shopping"

[...] O Flamboyant Shopping Center é o resultado de cinco anos de pesquisas minuciosas nas áreas mercadológicas e arquitetônica, feitas com a acessoria de empresas americanas que de-

\footnotetext{
${ }^{9}$ Encarte do jornal O Popular, veiculado em 1981.
} 
têm o mais especializado know-how no setor, uma vez que são eles os introdutores do sistema. [...] Na praça quatro escadas rolantes com capacidade para transportar cinco mil pessoas por hora. (O Popular, 11 out. 1981)

Os textos destacados associam modernidade, desenvolvimento e shopping, lançando sobre as formas tradicionais de comércio uma espécie de mácula. O Flamboyant, como shopping center pioneiro em Goiânia, representou a afirmação de um outro modelo de cidade que, aos poucos, tornou-se hegemônico no Brasil. Sua consolidação e replicação em outros exemplares de mesmo porte ou menores trouxeram conseqüências importantes. Uma delas diz respeito à transformação do comércio na região central, que, num primeiro momento, tornou-se mais popular e, posteriormente, teve suas ruas ocupadas por vendedores ambulantes num sistema de comércio informal. As tentativas de reconquistas desses espaços públicos deram-se concomitantemente com o reconhecimento do patrimônio histórico, resumido em poucos edifícios no estilo art déco, glorificados em inúmeras publicações. Projetos de revitalização, particularmente um com o sugestivo nome "Cara Limpa", anunciam operações de gentricação também expressas na criação de um mercado aberto aos ambulantes agora devidamente organizados em barracas confeccionadas segundo um mesmo padrão elaborado pelo poder público.

Como os supermercados, e depois seus poderosos congêneres - os hipermercados -, o Flamboyant Shopping Center e seus duplos - atualmente são cinco estabelecimentos semelhantes em porte e importância -, anunciou, de fato, uma nova era da capital. Sua imagem refletida no espeIho do presente pouco lembra Versalhes ou as cidades-jardins que the serviram de referências iniciais. O spraw americano, as imagens de Miami ou Dallas parecem lançar raízes na terra das emas, atualmente aves entristecidas e confinadas ao jardim zoológico e, como observa Mello (2004), presenças indesejáveis nos condomínios horizontais fechados construídos nos subúrbios da cidade, depois da segunda metade dos anos de 1990.

Atualmente, o Flamboyant Shopping Center pouco lembra o edifício original de pretensa dignidade: no seu interior, havia intervenções de artistas renomados que criaram móbiles, painéis e alguma escultura. Acréscimos sucessivos, atualizações de revestimentos e a necessidade de novas vagas para estacionamento produziram protuberâncias, perturbando o arranjo das caixas. O local em que foi construído, às margens de uma estrada federal, distante dos bairros habitacionais e do centro da cidade, modificou-se expressivamente com a abertura e duplicação de vias, a construção de revendedoras Nissan e Peugeot, a instalação de um hotel pertencente a uma rede qualquer, a presença do Carrefour e de restaurantes - as infalíveis pizzas e os onipresentes McDonald's. Um relógio, construído em uma rótula cujo terreno foi artificialmente inclinado, marca o tempo sobre um plano de flores, cuidadosamente aparadas. De tão bem cuidado, esse relógio parece ser obra de um relojoeiro suíço, seqüestrado de uma pequenina cidade alpina, não fosse o fato de estar sempre atrasado. 
A cidade ultrapassou a rodovia e, sob a frondosa sombra do Flamboyant, inúmeros condomínios horizontais estão em construção, com inquietantes nomes como Jardim Atenas, Jardim Paris, Aldeia do Vale, AlphaVille, esse último um empreendimento com realizações em várias capitais brasileiras e também em Portugal.

Goiânia parece, finalmente, cumprir o seu destino: tornar-se mais uma São Paulo, Buenos Aires ou cidade do México, guardando - é claro - as devidas proporções. As semelhanças entre essas cidades e tantas outras espalhadas no pequeno planeta Terra enquadra-se numa espécie de fórmula algébrica que poderia ser expressa nos termos:

$$
\mathrm{CG}=\underline{(\mathrm{EA}+\mathrm{CH}+\mathrm{CF}+\mathrm{SH}) \times \text { consumo }}
$$

$P$

Por CG entende-se Cidade Genérica que, para Koolhaas (2001), é sinônimo das cidades asiáticas e outras do hemisfério sul, as quais possuem uma frenética dinâmica de construção e destruição. Tudo o que nelas existe é feito para o presente, portanto, nada para durar na medida em que respondem às contingências hodiernas. $O$ termo genérico utilizado para referir-se às cidades asiáticas tem como sinônimo a palavra geral e por antônimo específico. Atualmente, utiliza-se o adjetivo genérico, migrado do francês para o português por volta de 1596, para designar medicamentos similares àqueles produzidos por poderosos laboratórios, sem que com isso sejam pagos vultosos royalties. Genérico, em última instância, é o equivalente.

Seguindo os termos da fórmula algébrica, EA refere-se aos eventos arquitetônicos, obras assinadas por arquitetos internacionalmente reputados que têm o poder de dar visibilidade a locais desconhecidos. $\mathrm{CH}$ diz respeito às operações de gentrificação e patrimonialização dos centros históricos, engessados em nome de "comoventes" memórias. Por sua vez, CF concerne aos condomínios fechados, o mais emblemático sucesso do Novo Urbanismo de origem americana, cujas referências iniciais encontram-se em Seaside, em Miami, projetado por Andres Duany e Elizabeth Plater-Zyberk, nos anos de 1980. À imagem das cidades e bairros-jardins, esses parcelamentos habitacionais proliferam virulentamente. São vendidos e consumidos sob o slogan da "qualidade de vida, segurança, e proximidade com a natureza" - pode-se ouvir o chilrear dos passarinhos, ou o barulho medonho dos carros que transitam na auto-estrada ou nas competições do autódromo, localizado em suas vizinhanças, como é o caso dos condomínios mencionados. Por fim, mas não menos importante, SH concentra duas formas de distribuição e consumo: os shoppings e os hipermercados. Os termos do numerador estão multiplicados pelo consumo e divididos pelo planeta, daí a letra P para o denominador.Não importa que valores substituam as variáveis da equação da cidade genérica, o resultado será sempre parecido, mesmo que diferente. Sua lógica é única. 


\section{Referências}

BENJAMIN, Walter. Paris, capitale du XIXe siecle. Tradução do alemão: Jean Lacoste. $3^{a}$ edição. Paris: Lês Éditions du cerf, 2000.

CASTRO, Silvio. A Carta de Pedro Vaz de Caminha: o descobrimento do Brasil. Porto Alegre: L\&PM, 2003.

CHA, Talwook et al. Shopping (Harvard Project on the city). In: KOOLHAAS, Rem et al. Mutations. Bordeaux: Arc em Revê Centre d'Architecture, 2001.

CRAWFORD, Margaret. El mundo en un centro commercial. In: SORKIN, Michel (Org.). Variaciones sobre un parque temático: la nueva ciudad americana y el fin del espacio público. Barcelona: Gili Mixta, 2004.

FLAMBOYANT Shopping Center: empreendimento que representa a maturidade técnica e econômica. Folha de Goiáz, 8 maio 1980. p.11.

SILVA, Geraldo Gomes da. Arquitetura do ferro no Brasil. 2aㅡ. ed. São Paulo: Nobel, 1987.

HERMAN, Daniel. Mall: requiem for a type. In: KOOLHAAS, Rem et al. Project on the city 2: the Harvard design school Guide to Shopping. Los Angeles: Taschen, 2001.

KOOLHAAS, Rem. Delirio de Nueva York. Tradução para o espanhol de Jorge Sainz. Barcelona: Gili, 2004.

KOOLHAAS, Rem et al. Mutations. Bordeaux: Arc em Revê Centre d'Architecture, 2001a.

KOOLHAAS, Rem et al. Project on the city 2: the Harvard design school Guide to Shopping. Los Angeles: Taschen, 2001b.

KÜHL, Beatriz Mugayar. Arquitetura do ferro e arquitetura ferroviária em São Paulo: reflexões sobre a sua preservação. São Paulo: Ateliê Editorial: Fapesp: Secretaria da Cultura, 1998.

LANÇADA maquete do Flamboyant Center. O Popular, 10 maio 1980.

LEITE, Marley Costa. Goiânia 48 anos, 800.000 habitantes, entra na era do shopping. O Popular, 11 out. 1981, Caderno 2. p.36.

MELLO, Márcia Metran. Goiânia: cidade de pedras e de palavras. 2004. Tese (Doutorado em Sociologia) - Universidade de Brasília, Brasília, DF.

PEIXOTO, Elane Ribeiro. Arquitetura na revista Projeto (1980-1995): identidade, memória e não-lugares, 2003. Tese (Doutorado em Arquitetura e Urbanismo) - Universidade de São Paulo, São Paulo.

SCHWARCZ, Lilia Moritz. As barbas do imperador: D. Pedro II, um monarca nos trópicos. São Paulo: Companhia das Letras, 1998.

VENTURI, Robert; BROWN, Denise Scott; IZENOUR, Steven. Aprendendo com Las Vegas: o simbolismo (esquecido) da forma arquitetônica. Tradução de Pedro Maia Soares. São Paulo: Cosac \& Naify, 2003.

WEISS, Srdjan Jovanovic, LEONG, Sze Tsung. Escalator: mechanism of smootheness. In: KOOLHAAS, Rem et al. Project on the city 2: the Harvard design school Guide to Shopping. Los Angeles: Taschen, 2001. 